\title{
Cytology vs molecular analysis for the detection of head and neck squamous cell carcinoma in oesopharyngeal brush samples: a prospective study in 56 patients
}

\author{
S Temam', M Trassard ${ }^{2}$, G Leroux', J Bosq ${ }^{3}$, B Luboinski', G Lenoir ${ }^{4}$, J Bénard ${ }^{4}$ and F Janot ${ }^{*, I}$ \\ 'Head and Neck Surgery Department, Institut Gustave-Roussy, 39 rue Camille Desmoulins, Villejuif 94805, France; ${ }^{2}$ Pathology Department, \\ Centre René Huguenin, St Cloud 922 10, France; ${ }^{3}$ Pathology Department, Institut Gustave-Roussy, Villejuif 94805, France; ${ }^{4}$ Genetics Department, \\ Institut Gustave-Roussy, Villejuif 94805, France
}

\begin{abstract}
Oesopharyngeal brush (OPB) sampling with cytological analysis can yield exfoliated cells from asymptomatic tumours of the upper aero-digestive tract and the oesophagus. In this study, we compared cytological evaluation and molecular analysis for the detection of exfoliated cancer cells sampled with an OPB. A total of 56 patients with a known unique head and neck squamous cell carcinoma (HNSCC) and five healthy controls were enrolled prospectively. Exfoliated cells from these $6 \mathrm{I}$ patients were collected with an OPB before initial endoscopy. P53 mutations and UT 5085 microsatellite instability (MI) were analysed in the HNSCC tumour, lymphocytes and the corresponding OPB DNA samples. p53 mutations and UT5085 MI were detected in 3I out of 56 and I4 out of 56 HNSCC, respectively, but not in any of the five controls. Direct sequencing of p53 was able to detect mutations in OPB DNA in only two out of 29 patients harbouring a p53-mutated primary tumour. Microsatellite instability was detected in OPB DNA of I I out of I 3 informative (bandshift detected in tumour) patients, whereas cytological analysis detected abnormal cells in only six of the same 13 patients $(P=0.03)$. In informative patients, all positive OPB samples at cytological analysis were also positive at molecular analysis of UT5085, and both analyses confirmed the two negative samples. Molecular analysis of OPB from eight uninformative patients and from five healthy controls were all negative. OPB sampling with Ml-based molecular analysis could be efficient for early detection of recurrent HNSCC. This result prompts us to use other microsatellite markers in order to maximise the percentage of informative patients. British Journal of Cancer (2003) 88, I740- 1745. doi:I0.1038/sj.bjc.6600953 www.bjcancer.com (c) 2003 Cancer Research UK
\end{abstract}

Keywords: genetic markers; microsatellite repeats; cytodiagnosis; p53 gene; head and neck carcinoma

With 23000 new cases annually, the incidence of head and neck squamous cell carcinoma (HNSCC) in France is one of the highest in the world (Hill et al, 1997) because of smoking and alcohol consumption (IARC, 1986, 1988). Early detection of HNSCC could improve therapeutic results and reduce morbidity and mortality. Loco-regional relapses occur in more than $30 \%$ of HNSCC patients and mostly during the first 2 years after treatment (McCarty and Million, 1994; Haas et al, 2001). Salvage treatments can only be effective if recurrences are detected rapidly. The incidence of second primary metachronous HNSCC attains $2-4 \%$ annually and these lesions also need to be detected early (Panosetti et al, 1989; Erkal et al, 2001). However, after surgery and/or radiotherapy, clinical and radiological surveillance is difficult because of anatomical modifications and fibrosis. Both clinical and nasofibroscopic examinations are only limited to the upper part of the aero-digestive tract (Boysen et al, 1992). Cytological screening (Ogden, 1997) has been developed by collecting saliva with or without an oral mucosal brush. Recently, an encapsulated oesopharyngeal brush (OPB) technique for cytological analysis was developed to detect recurrent and metachronous oesophageal carcinomas (Leoni-Parvex et al, 2000). Oesopharyngeal brush has

*Correspondence: Dr F Janot; E-mail: janot@igr.fr

Received 15 November 2002; revised 30 January 2003; accepted 10 February 2003 also been shown to be capable of collecting exfoliated cells from oral or pharyngeal carcinoma. This technique, whose sensitivity and specificity are high, appears to be safe and minimally invasive.

Head and neck squamous cell carcinoma is a multistep genetic process (Califano et al, 1996; Mao et al, 1996a) during which protooncogenes are activated and tumour-suppressor genes are inactivated. Tri- and tetranucleotide microsatellite instability (MI) is characterised by the insertion or deletion of one or more repeat units of three or four nucleotides. These sporadic microsatellite mutations are independent of mutations in mismatch repair genes and reflect DNA damage caused by exposure to carcinogens in tobacco smoke (Slebos et al, 2002). Microsatellite instability is regarded as a clonal marker of HNSCC (Mao et al, 1994; Coulet et al, 2000), which can be used to detect small amounts of tumour DNA (Forastiere et al, 2001). Microsatellite instability is a qualitative variable that can be detected by PCRbased techniques such as bandshift assays. The UT5085 marker currently appears to be the most informative marker of MI in HNSCC (Coulet et al, 2000). The p53 tumour-suppressor gene is mutated in more than $50 \%$ of HNSCC (Temam et al, 2000). Different PCR techniques have been described for the detection of p53 mutations. The sensitivity and the reproducibility of PCR have recently been reviewed (van Houten et al, 2000). The most sensitive techniques, including cDNA cloning and specific hybridisation, are very time consuming and are difficult to apply in routine practice. 
Molecular approaches have rarely been compared with conventional cytological analysis in HNSCC (Mao et al, 1994). The aim of the present study was to test the OPB for the detection of tumour cells from the head and neck region, and to compare conventional cytological evaluation with molecular analysis using two techniques: analysis of MI at the UT5085 locus and direct sequencing of p53.

\section{MATERIALS AND METHODS}

\section{Patients and sample collection}

Patients were referred to the Institut Gustave Roussy between July 1999 and June 2000. All patients underwent OPB sampling before panendoscopy with oesophagoscopy, which excluded a second oesophageal tumour. Oesopharyngeal brush sampling was performed, as previously described (Leoni-Parvex et al, 2000). An abrasive sponge wrapped in a capsule (Oesotest ${ }^{\mathbb{R}}$, Biodessa, France) was first swallowed and then withdrawn with a string. It was shaken in a saline fluid that was centrifuged over $10 \mathrm{~min}$ at $3000 \mathrm{~g}$. The supernatant was discarded and the cell pellet was retained. Part of this pellet was smeared onto three glass slides and fixed in alcohol. Slides were stained using the Papanicolaou method for cytological evaluation and the rest of the sediment was frozen for biological studies. The institutional review board approved the study, and informed consent was obtained from all subjects.

In total, 56 fresh-frozen primary HNSCC biopsy samples were collected during panendoscopy from 56 patients. All samples were diagnosed as invasive HNSCC and samples containing more than $70 \%$ of tumour cells were selected in order to avoid microdissection. Normal mucosa biopsy specimens were also collected during panendoscopy from five healthy patients, who were heavy smokers and drinkers, but free of HNSCC. At the time of the initial diagnosis, fresh blood was collected from patients in EDTA tubes and lymphocytes were separated for use as normal DNA.

\section{Cytological criteria}

Cytological specimens were considered positive if there were lowor high-grade squamous dysplastic cells or squamous carcinoma cells, at least on one slide. This definition of positivity was based on oeosophageal cytological criteria proposed by Shu (1983) and used by others (Leoni-Parvex et al, 2000). The cytological evaluation was considered negative only when there was no significant cytonuclear atypia in squamous cells and if the majority of cells were of the intermediate type.

\section{Analysis of UT5085 microsatellite in tumour DNA and OPB samples}

DNA was extracted with the QIAamp Blood Kit (Qiagen, Courtaboeuf, France). DNA quality was checked with GeneQuant II (Amersham Pharmacia Biotech, Cambridge, UK). The UT5085 tetranucleotidic microsatellite was amplified with primers referenced in the GenBank sequence database (accession number GDB 309286), as described (Coulet et al, 2000): (a) UT5085A, 5' AAAGTGGGGATAAGGCAGC- ${ }^{\prime}$; and (b) UT5085B, 5' -AGATGCACAACACATACACG- $3^{\prime}$. The primer (a) UT5085A was labelled in blue by 6-carboxy-fluorescein (FAM). Amplification was performed in a $20-\mu$ l reaction volume with $0.5 \mathrm{U}$ HotStart Taq DNA Polymerase (Qiagen, Courtaboeuf, France), $0.2 \mathrm{~mm}$ deoxynucleotide triphosphate, $3.2 \mathrm{pmol}$ of each forward and reverse primer, $2 \mathrm{~mm} \mathrm{MgCl} 2$, and $2 \mu \mathrm{l}$ of $10 \times$ Qiagen buffer. A total of $100 \mathrm{ng}$ of DNA was used as a template for each sample. The mixtures were denatured for $20 \mathrm{~min}$ at $95^{\circ} \mathrm{C}$ followed by 35 cycles at $95^{\circ} \mathrm{C}$ for $30 \mathrm{~s}$, $54^{\circ} \mathrm{C}$ for $30 \mathrm{~s}$ and $72^{\circ} \mathrm{C}$ for $30 \mathrm{~s}$. A final elongation was performed for $10 \mathrm{~min}$ at $72^{\circ} \mathrm{C}$. Amplified products were run in polyacrylamide sequencing gels, ELLIOSEQ GEL (Laboratoires Ellios Bio Media, Paris, France) mixed with $0.5 \mu$ l of GENESCAN-500 ROX (Applied Biosystems, Inc., Warrington, UK) and $2.5 \mu \mathrm{l}$ of formamide blue after a 2 min denaturing step at $94^{\circ} \mathrm{C}$. Polymerase chain reaction (PCR) products were detected on the gel by laser fluorescence on the ABI prism 377 DNA sequencer (Applied Biosystems, Inc.). Data were analysed by Genescan analysis (Applied Biosystems, Inc.).

All tumours and corresponding lymphocytes were amplified to select unstable UT5085 samples. A normal mucosa biopsy specimen was used for the five control patients. Microsatellite instability (MI) was defined as the presence of a new pattern in at least one extra band in tumour DNA compared to lymphocyte DNA. Patients with UT5085 MI in tumours were defined as informative patients.

Oesopharyngeal brush material corresponding to all shifted tumours was then amplified and coanalysed with tumour and lymphocyte DNA to compare the different microsatellite patterns. We also studied OPB samples from eight uninformative tumours and from the five control subjects. Two observers assessed all samples independently and borderline cases were repeated and evaluated by densitometry.

\section{p53 mutation detection in tumour DNA and OPB samples}

Exons 2-11 were screened for mutations by denaturing highperformance liquid chromatography (DHPLC) using the Wave ${ }^{\circledR}$ (Transgenomic, Inc., Omaha, USA). Tumours with a variant chromatographic pattern were specifically amplified by PCR and both strands were sequenced for each variant exon using the $\mathrm{ABI}$ prism 377 DNA sequencer (Applied Biosystems, Inc.) with the Big Dye Terminator sequencing kit (Applied Biosystems, Inc). Data were analysed by Sequencing Analysis Software (Applied Biosystems, Inc). All mutations were confirmed twice on both strands.

Oesopharyngeal brush material from patients harbouring a p53mutated tumour was analysed to search for the same p53 mutation. We used direct sequencing of the putative mutated exon under the same conditions as in the tumour.

\section{Statistical analysis}

$\chi^{2}$ tests were used to compare qualitative variables.

\section{RESULTS}

\section{Population}

In total, 56 patients with a unique HNSCC were prospectively entered into the study. Primary tumour sites were: the oral cavity, oropharynx, larynx and hypopharynx in 13, 23, 12 and eight cases, respectively. There were 18 T1-2 and 38 T3-4 lesions (Table 1). Five healthy control patients, who were heavy smokers and drinkers but free of HNSCC, were also studied.

\section{Molecular markers in primary tumours}

UT5085 tetranucleotide MI was analysed in all tumours and corresponding lymphocytes (Table 1). Tumours were informative (i.e. exhibited a bandshift) in only 14 out of $56(25 \%)$ patients and not in five controls. p53 mutations were detected in 31 out of 56 (55\%) tumours. Of the p53 mutations, 21 (68\%) were missense mutations, nine (29\%) were nonsense mutations and one (3\%) was a silent mutation. Details of p53 mutations are shown in Table 2. There was no relation between molecular analysis results and the $\mathrm{T}$ stage or tumour location. No significant correlation was found between p53 mutations and UT5085 MI: nine out of 14 (64\%) tumours with UT 5085 MI were p53 mutated vs 22 out of 42 without MI $(52 \% ; P=0.6)$. 
Table I Clinical and biological characteristics of the 56 HNSCCs, according to cytological and biological study of pharyngo-oesophageal brushing $\left(\right.$ Oesotest ${ }^{\circledR}$ )

\begin{tabular}{|c|c|c|c|c|c|c|c|}
\hline \multirow[b]{2}{*}{ Pts no. } & \multirow[b]{2}{*}{ Tumour site } & \multirow[b]{2}{*}{ T stage } & \multirow{2}{*}{$\begin{array}{l}\text { Cytology } \\
\text { Oesotest }\end{array}$} & \multicolumn{2}{|c|}{ Microsatellite UT5085 } & \multicolumn{2}{|c|}{ p53 mutations } \\
\hline & & & & Tumour & Oesotest & Tumour & Oesotest \\
\hline I & Oropharynx & $\mathrm{T} 4$ & Carcinoma & Shift & Shift & Mut & Neg \\
\hline 2 & Oropharynx & T3 & Neg & Shift & Shift & Mut & Mut \\
\hline 3 & Oropharynx & $\mathrm{T} 4$ & Neg & Shift & Shift & Mut & Neg \\
\hline 4 & Larynx & $\mathrm{T} 2$ & Carcinoma & Shift & Shift & Mut & Neg \\
\hline 5 & Larynx & $\mathrm{T} 4$ & Carcinoma & Shift & Shift & Mut & Neg \\
\hline 6 & Hypopharynx & $\mathrm{T} 2$ & Neg & Shift & Shift & Mut & Neg \\
\hline 7 & Oral cavity & $\mathrm{T} 4$ & High-grade dysplasia & Shift & Shift & Mut & Neg \\
\hline 8 & Oropharynx & $\mathrm{T} 4$ & Carcinoma & Shift & Shift & Wild & ND \\
\hline 9 & Oropharynx & $\mathrm{T} 2$ & Carcinoma & Shift & Shift & Wild & ND \\
\hline 10 & Hypopharynx & $\mathrm{T} 4$ & Neg & Shift & Shift & Wild & ND \\
\hline |1 & Oral cavity & $\mathrm{T} 4$ & Neg & Shift & Shift & Wild & ND \\
\hline 12 & Larynx & T3 & Neg & Shift & Neg & Mut & Neg \\
\hline 13 & Oropharynx & $\mathrm{T} 4$ & Neg & Shift & Neg & Wild & ND \\
\hline 14 & Oropharynx & T3 & Neg & Shift & No DNA & Mut & No DNA \\
\hline 15 & Hypopharynx & $\mathrm{T} 4$ & Carcinoma & Neg & Neg & Mut & Mut \\
\hline 16 & Oropharynx & T3 & Carcinoma & Neg & Neg & Mut & Neg \\
\hline 17 & Oropharynx & $\mathrm{T} 4$ & Neg & Neg & ND & Mut & Neg \\
\hline 18 & Oropharynx & T3 & Neg & Neg & ND & Mut & Neg \\
\hline 19 & Oropharynx & $\mathrm{T} 4$ & High-grade dysplasia & Neg & ND & Mut & Neg \\
\hline 20 & Oropharynx & $\mathrm{T} 4$ & Carcinoma & Neg & ND & Mut & Neg \\
\hline 21 & Oropharynx & $\mathrm{T} 2$ & Neg & Neg & ND & Mut & Neg \\
\hline 22 & Oropharynx & $\mathrm{T} 2$ & Neg & Neg & ND & Mut & Neg \\
\hline 23 & Oropharynx & T3 & Low-grade dysplasia & Neg & ND & Mut & Neg \\
\hline 24 & Oropharynx & $\mathrm{T} 2$ & Carcinoma & Neg & ND & Mut & Neg \\
\hline 25 & Larynx & T3 & Carcinoma & Neg & Neg & Mut & Neg \\
\hline 26 & Larynx & T3 & $\mathrm{Neg}$ & Neg & Neg & Mut & Neg \\
\hline 27 & Larynx & $\mathrm{T} 4$ & Neg & Neg & ND & Mut & Neg \\
\hline 28 & Larynx & $\mathrm{T} 2$ & Low-grade dysplasia & Neg & ND & Mut & Neg \\
\hline 29 & Hypopharynx & $\mathrm{T} 2$ & Carcinoma & Neg & ND & Mut & Neg \\
\hline 30 & Hypopharynx & $\mathrm{T} 4$ & Neg & Neg & Neg & Mut & Neg \\
\hline 31 & Hypopharynx & $\mathrm{TI}$ & Neg & Neg & Neg & Mut & ND \\
\hline 32 & Hypopharynx & $\mathrm{T} 4$ & Neg & Neg & ND & Mut & Neg \\
\hline 33 & Oral cavity & $\mathrm{T} 4$ & Neg & Neg & ND & Mut & Neg \\
\hline 34 & Oral cavity & $\mathrm{T} 4$ & Neg & Neg & Neg & Mut & Neg \\
\hline 35 & Oral cavity & T3 & Neg & Neg & Neg & Mut & Neg \\
\hline 36 & Oral Cavity & T3 & Neg & Neg & ND & Mut & Neg \\
\hline 37 & Oropharynx & TI & Carcinoma & Neg & Neg & Wild & ND \\
\hline 38 & Oropharynx & T3 & Neg & Neg & ND & Wild & ND \\
\hline 39 & Oropharynx & $\mathrm{T} 2$ & Neg & Neg & ND & Wild & ND \\
\hline 40 & Oropharynx & $\mathrm{T} 2$ & Neg & Neg & ND & Wild & ND \\
\hline 41 & Oropharynx & T3 & Neg & Neg & ND & Wild & ND \\
\hline 42 & Oropharynx & $\mathrm{T} 2$ & Neg & Neg & ND & Wild & ND \\
\hline 43 & Oropharynx & $\mathrm{TI}$ & Neg & Neg & ND & Wild & ND \\
\hline 44 & Larynx & $\mathrm{T} 4$ & Neg & Neg & ND & Wild & ND \\
\hline 45 & Larynx & $\mathrm{T} 2$ & Low-grade dysplasia & Neg & ND & Wild & ND \\
\hline 46 & Larynx & T3 & High-grade dysplasia & Neg & ND & Wild & ND \\
\hline 47 & Larynx & $\mathrm{T} 4$ & Neg & Neg & ND & Wild & ND \\
\hline 48 & Larynx & TI & Neg & Neg & Neg & Wild & ND \\
\hline 49 & Hypopharynx & $\mathrm{T} 4$ & Neg & Neg & ND & Wild & ND \\
\hline 50 & Oral cavity & $\mathrm{T} 2$ & Neg & Neg & ND & Wild & ND \\
\hline 51 & Oral cavity & $\mathrm{T} 4$ & Neg & Neg & ND & Wild & ND \\
\hline 52 & Oral cavity & $\mathrm{T} 4$ & Neg & Neg & ND & Wild & ND \\
\hline 53 & Oral cavity & $\mathrm{T} 4$ & High-grade dysplasia & Neg & ND & Wild & ND \\
\hline 54 & Oral cavity & $\mathrm{T} 4$ & Carcinoma & Neg & ND & Wild & ND \\
\hline 55 & Oral cavity & T3 & $\mathrm{Neg}$ & Neg & ND & Wild & ND \\
\hline 56 & Oral cavity & $\mathrm{T} 2$ & $\mathrm{Neg}$ & Neg & ND & Wild & ND \\
\hline
\end{tabular}

Neg = negative; ND = not done; shift = microsatellite instability at UT5085; Mut = p53 mutation; Wild = p53 wild type.

\section{Cytological analysis and molecular markers in OPB samples}

All cytological samples were available for interpretation. Of the 56 OPB DNA samples, $20(36 \%)$ were positive at cytological examination: 13 with squamous carcinoma cells and seven with dysplastic cells (Table 1). There was no relation between the results of the cytological analysis and the $\mathrm{T}$ stage or tumour location. Oesopharyngeal brush cytology was normal in all five control subjects.

Oesopharyngeal brush DNA was available for the evaluation of UT5085 tetranucleotide MI in 13 out of 14 informative patients. In these informative patients, a bandshift, similar to that observed in the primary tumour, was detected in 11 out of 13 (85\%) OPB DNA 
Table 2 p53 mutations in 31 patients with HNSCC

\begin{tabular}{|c|c|c|c|c|}
\hline Patients no. & Exon & Codon $^{a}$ & Sequence & Amino acid \\
\hline 28 & 4 & 35 & Deletion I bp & Frameshift \\
\hline 35 & 4 & 111 & $\mathrm{CTG} \rightarrow \mathrm{CAG}$ & $\mathrm{L} \rightarrow \mathrm{Q}$ \\
\hline 18 & 5 & 125 & $\mathrm{ACG} \rightarrow \mathrm{AGG}$ & $\mathrm{T} \rightarrow \mathrm{R}$ \\
\hline 27 & 5 & 126 & $\mathrm{TAC} \rightarrow \mathrm{TGC}$ & $Y \rightarrow C$ \\
\hline 31 & 5 & 134 & $\mathrm{~T} \mathrm{~T} \rightarrow \mathrm{GTT}$ & $\mathrm{F} \rightarrow \mathrm{V}$ \\
\hline 30 & 5 & 146 & $\mathrm{TGG} \rightarrow \mathrm{TAG}$ & $W \rightarrow$ Stop \\
\hline 36 & 5 & 179 & $\mathrm{CAT} \rightarrow \mathrm{CTT}$ & $H \rightarrow L$ \\
\hline 34 & 5 & 183 & $\mathrm{TCA} \rightarrow \mathrm{TGA}$ & $S \rightarrow$ Stop \\
\hline 3 & 5 & 187 & $\mathrm{GGT} \rightarrow \mathrm{GTT}$ & $\mathrm{G} \rightarrow \mathrm{V}$ \\
\hline I & 6 & 193 & $\mathrm{CAT} \rightarrow \mathrm{CTT}$ & $H \rightarrow L$ \\
\hline 12 & 6 & 204 & $\mathrm{GAG} \rightarrow \mathrm{TAG}$ & $E \rightarrow$ Stop \\
\hline 7 & 7 & 245 & $\mathrm{GGC} \rightarrow \mathrm{GAC}$ & $\mathrm{G} \rightarrow \mathrm{V}$ \\
\hline 2 & 7 & 247 & $\mathrm{AAC} \rightarrow \mathrm{AAT}$ & $\mathrm{N} \rightarrow \mathrm{N}$ \\
\hline 24 & 7 & 248 & $\mathrm{CGC} \rightarrow \mathrm{CTG}$ & $\mathrm{R} \rightarrow \mathrm{L}$ \\
\hline 19 & 7 & 248 & $\mathrm{CGG} \rightarrow \mathrm{CAG}$ & $R \rightarrow L$ \\
\hline 15 & 7 & 257 & Insertion I bp & Frameshift \\
\hline 26 & 8 & 270 & $\mathrm{~T} \mathrm{~T} \rightarrow \mathrm{TCT}$ & $\mathrm{F} \rightarrow \mathrm{S}$ \\
\hline $32,33,20$ & 8 & 273 & $\mathrm{CGT} \rightarrow \mathrm{TGT}$ & $R \rightarrow C$ \\
\hline 14 & 8 & 273 & $\mathrm{CGT} \rightarrow \mathrm{CAT}$ & $\mathrm{R} \rightarrow \mathrm{H}$ \\
\hline 23 & 8 & 275 & $\mathrm{TGT} \rightarrow \mathrm{TT}$ & $C \rightarrow F$ \\
\hline $4,29,17,21$ & 8 & 282 & $\mathrm{CGG} \rightarrow \mathrm{TGG}$ & $R \rightarrow W$ \\
\hline 5 & 9 & 319 & $\mathrm{AAG} \rightarrow \mathrm{TAG}$ & $K \rightarrow$ Stop \\
\hline 16 & 9 & 321 & Deletion I bp & Frameshift \\
\hline 25 & 9 & 331 & $\mathrm{CAG} \rightarrow \mathrm{TAG}$ & $Q \rightarrow$ Stop \\
\hline 6 & 9 & 327 or 328 & Insertion I bp & Frameshift \\
\hline 22 & 10 & Intron II & $17708 \mathrm{~A} \rightarrow \mathrm{T}$ & Silent \\
\hline
\end{tabular}

${ }^{a}$ First codon of the frameshift mutation.

$\mathrm{bp}=$ base pair
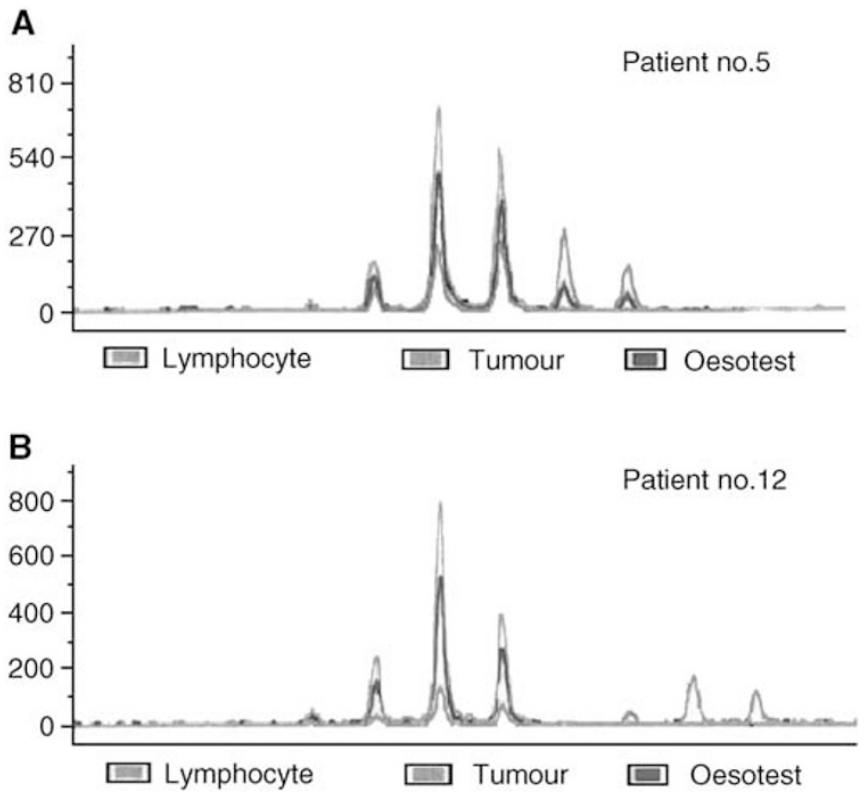

Figure I Microsatellite UT5085 of paired tumour, lymphocyte and pharyngo-oesophageal brushing (Oesotest ${ }^{\mathbb{R}}$ ). (A) Patient number 5 who had an informative tumour (bandshift) and a positive brushing with the same pattern (same bandshift as tumour). (B) Patient number 12 who had an informative tumour and a negative brushing.

samples (Figure 1A). In the same samples, tumour cells were detected at cytological analysis in only six out of $13(46 \%)$ patients. In informative patients all positive OPB DNA samples at cytological evaluation were also positive at molecular analysis of UT5085 (Table 3), and the two samples found to be negative at molecular analysis were also negative at cytological analysis (Figure 1B). In this subgroup, the molecular analysis with the
Table 3 Comparison of cytological examination with Papanicolaou staining and microsatellite analysis of pharyngo-oesophageal brush samples for the 13 patients whose tumour exhibited an MI at UT5085

\begin{tabular}{lccc}
\hline & \multicolumn{2}{c}{ Cytology } & \\
\cline { 2 - 3 } & Positive $^{\mathbf{a}}$ & Negative & Total \\
\hline Microsatellite UT5085 & & 5 & \\
Shift & 6 & 2 & 11 \\
No shift & 0 & 7 & 2 \\
Total & 6 & 13 \\
\hline
\end{tabular}

Molecular analysis was more sensitive than cytological study $(P=0.03)$.

${ }^{a}$ Positive $=$ low- or high-grade squamous dysplasia cells or squamous cells carcinoma.

Table 4 Comparison of cytological examination with Papanicolaou staining and p53 direct sequencing of pharyngo-oesophageal brushing for the 29 patients with p53 mutated tumours

\begin{tabular}{lccc}
\hline & \multicolumn{2}{c}{ Cytology } & \\
\cline { 2 - 3 } & Positive $^{\mathbf{a}}$ & Negative & Total \\
\hline Mutated p53 & 1 & 1 & \\
Yes & 12 & 15 & 2 \\
No & 13 & 16 & 27 \\
Total & 13 & 29 \\
\hline
\end{tabular}

${ }^{\text {a }}$ ositive $=$ low- or high-grade squamous dysplasia cells or squamous cells carcinoma.

UT5085 marker was more sensitive than the cytological analysis $(P=0.03)$. Molecular analysis with UT5085 was negative for the 13 controls: five healthy subjects and eight uninformative patients.

In the subgroup of 31 patients exhibiting a p53 mutation, DNA was available for $29 \mathrm{OPB}$ samples. Direct sequencing of p53 was able to detect tumour DNA in OPB samples from only two out of $29(7 \%)$ samples, whereas cytological evaluation was positive in 13 out of 29 OPB samples (45\%; Table 4). Of these 13 OPB DNA samples, 12 were positive at cytological analysis and negative at direct sequencing of p53.

\section{DISCUSSION}

Oesopharyngeal brush with cytological analysis was mainly developed in China for mass screening of oesophageal carcinoma (Dowlatshahi et al, 1978; Jaskiewicz et al, 1987). The sensitivity of this technique ranges from 40 to $70 \%$ and its specificity from 90 to $99 \%$. Several teams have used the OPB to detect second primary tumours during the follow-up of patients treated for HNSCC, because clinical examination is difficult and is limited to the upper part of the aero-digestive tract. The OPB has indeed proved very sensitive for the detection of new primary lesions. In the study by Pellanda et al (1999), none of the 254 patients with negative OPB cytology developed an oesophageal tumour. Among the 25 asymptomatic patients with positive OPB cytology, a premalignant or early oesophageal tumour was detected in 20 cases. Interestingly, in the same study 10 clinically unsuspected oral or pharyngeal carcinoma were also detected. These data suggest that exfoliated cells from the upper part of the aero-digestive tract can be swallowed and sampled with the OPB. This technique for collecting tumour cells could therefore be as efficient as saliva sampling with the added advantage of allowing access to the hypopharynx and oesophagus. In the present study, the OPB was used before endoscopy and the initial biopsy. The oesophagoscopy excluded a second primary tumour of the oesophagus. 
The aims of our study were two-fold: (i) to test the capacity of the OPB in detecting tumour cells from inaccessible parts of the head and neck region and (ii) to compare cytological $v s$ molecular analysis for the detection of tumour exfoliated cells in a population of 56 HNSCC patients.

We confirm that tumour cells exfoliated from the head and neck region can be sampled in the oesophagus. It is noteworthy that OPB detected tumour cells and/or tumour DNA in seven out of 12 laryngeal carcinoma in the oesophagus, as shown in Table 1. Perhaps, this easy and low-invasive technique could be tested in bronchial carcinoma.

The results of the molecular analysis of OPB samples are directly linked to the technique used. In this study, we tested two different techniques: MI analysis and p53 direct sequencing. Microsatellite alterations on selected tetranucleotide markers are common in non-small-cell lung, head and neck, and bladder carcinoma (Mao et al, 1994). The generation of a novel allele through the insertion or deletion of a short tandem repeat creates a new band that is only present in neoplastic cells. This new band is easier to detect than a subtle change as in loss of heterozygosity. Our results show that for informative patients, molecular analysis with UT 5085 appears to be more sensitive than cytology for the detection of exfoliated tumour cells: abnormal DNA was detected in 11 out of 13 OPB samples, compared to six out of 13 abnormal or tumour cells detected at cytology $(P=0.03)$. These results will prompt us to use panels of microsatellite markers, in order to increase the sensitivity of the genetic analysis. Using a panel of 23 informative microsatellite markers, Spafford et al (2001) found a much higher rate (57 vs 25\%) of MI in HNSCC patients.

Mao et al (1994), using a panel of nine tri- and tetranucleotide markers, demonstrated the interest of MI as clonal markers for the detection of HNSCC cells. They detected identical microsatellite alterations in corresponding serum, sputum and surgical margins. In patients treated for bladder carcinoma, microsatellite analysis of urine sediment was found to be more efficient than cytological analysis: primary bladder cancer was identified in 19 out of 20 patients at microsatellite analysis, whereas only nine out of 18 lesions were detected at cytological analysis (Mao et al, 1996b). Thus, in these informative patients, the difference between the two techniques (conventional cytological analysis and microsatellite analysis) is similar to that found in the present study. Studying pretreatment oral rinses and swab samples from HNSCC patients, Spafford et al detected MI in 24 out of 25 (96\%) informative patients. Like most authors, they did not, however, compare microsatellite detection and cytology (Spafford et al, 2001). Our study shows that microsatellite-based molecular analysis can be positive in cytologically negative samples.

In our experience, the bandshift profile detected in OPB samples must be compared with that of the primary tumour. DNA extracted from exfoliated cells can undergo degradation and it is mandatory that bandshifts be distinguished from artefacts. Microsatellite-based molecular analysis should be efficient for early detection of recurrences of a tumour that has already been analysed. However, unlike cytology, this technique will be difficult to use for the detection of second primary tumours, which do not necessarily share the same genetic alterations.

Conversely and based on the concept of field cancerisation, we cannot exclude the possibility that cells other than those of the primary tumour share the same genetic alterations. Mucosa exhibiting a normal appearance in patients with early cancer or premalignant lesions has been shown to harbour occult microsatellite alterations (Califano et al, 1996). However, we have evidenced that the molecular analysis of UT5085 in OPB samples from eight patients with an uninformative tumour and from five heavy smokers free of HNSCC were all negative.

Although we found a 55\% rate of p53 mutations in primary tumours, which is similar to that usually observed in HNSCC, only a $7 \%$ rate of p53 mutations was found in OPB samples from patients with p53 mutations. As shown by Boyle et al (1994), p53mutated cells are present in the saliva of HNSCC patients. They used another technique, namely cloning of p53 sequences followed by hybridisation with specific radio-labelled oligonucleotide probes (van Houten et al, 2000). Two independent papers have demonstrated the clinical relevance of that technique by investigating surgical margins of tumours from head and neck cancer patients (Brennan et al, 1995; Partridge et al, 2000). However, this sensitive and clinically validated technique is very time consuming and cannot be used in routine practice. Our results also confirm that direct sequencing of $\mathrm{p} 53$ is not a sensitive technique for detecting small amounts of tumour DNA. In the present work, we found no association between UT $5085 \mathrm{MI}$ and p53 mutations in the primary tumour. This is in contrast with the results reported by Ahrendt et al (2000) in non-small-cell lung cancer.

The MI rate for one marker is low. As this study clearly indicates that microsatellite-based techniques could be efficient for detecting early recurrences, we could increase the number of MI markers, as already performed by Spafford et al (2001), in order to maximise the rate of informative patients.

Other molecular markers have been tested for the diagnosis of minimal residual disease in HNSCC. A panel of molecular markers based on promoter hypermethylation of selected genes (SanchezCespedes et al, 2000; Rosas et al, 2001) could be of particular interest as well as mutations in mitochondrial DNA (Fliss et al, 2000; Sanchez-Cespedes et al, 2001; Ha et al, 2002). This study on patients with known HNSCC is the first step towards a molecular diagnosis test for the follow-up of patients with HNSCC. In the near future, these cytodiagnosis techniques associated with molecular analysis could be tested in populations of heavy drinkers and smokers. Patients with asymptomatic tumours detected with these molecular markers could thus benefit from early treatment.

\section{ACKNOWLEDGEMENTS}

We thank Jean-Charles Soria (Institut Gustave-Roussy, Villejuif, France) and Pierre Hainaut (International Agency for Research on Cancer, Lyon, France) for critical review and helpful discussions. In addition, we acknowledge all the clinicians at our institute for providing the samples. We thank Lorna Saint Ange for editing. We also thank Hervé Desse for providing us with the Oesotest capsule.

This work was supported in part by ARC (Association de Recherche Contre le Cancer, France) Grant ARC-9281 (to FJ) and a CRC (Contrat de Recherche Clinique IGR) 2000 grant (to ST) from the Cancer Centre.

\section{REFERENCES}

Ahrendt SA, Decker PA, Doffek K, Wang B, Xu L, Demeure MJ, Jen J, Sidransky D (2000) Microsatellite instability at selected tetranucleotide repeats is associated with p53 mutations in non-small cell lung cancer. Cancer Res 60: 2488-2491
Boyle JO, Mao L, Brennan JA, Koch WM, Eisele DW, Saunders JR, Sidransky D (1994) Gene mutations in saliva as molecular markers for head and neck squamous cell carcinomas. Am J Surg 168: $429-432$ 
Boysen M, Lovdal O, Tausjo J, Winther F (1992) The value of follow-up in patients treated for squamous cell carcinoma of the head and neck. Eur $J$ Cancer 28: 426 - 430

Brennan JA, Mao L, Hruban RH, Boyle JO, Eby YJ, Koch WM, Goodman SN, Sidransky D (1995) Molecular assessment of histopathological staging in squamous-cell carcinoma of the head and neck. $N$ Engl J Med 332: $429-435$

Califano J, van der Riet P, Westra W, Nawroz H, Clayman G, Piantadosi S, Corio R, Lee D, Greenberg B, Koch W, Sidransky D (1996) Genetic progression model for head and neck cancer: implications for field cancerization. Cancer Res 56: 2488-2492

Coulet F, Blons H, Cabelguenne A, Lecomte T, Lacourreye O, Brasnu D, Beaune P, Zucman J, Laurent-Puig P (2000) Detection of plasma tumor DNA in head and neck squamous cell carcinoma by microsatellite typing and p53 mutation analysis. Cancer Res 60: 707-711

Dowlatshahi K, Daneshbod A, Mobarhan S (1978) Early detection of cancer of oesophagus along Caspian Littoral. Report of a pilot project. Lancet 1: $125-126$

Erkal HS, Mendenhall WM, Amdur RJ, Villaret DB, Stringer SP (2001) Synchronous and metachronous squamous cell carcinomas of the head and neck mucosal sites. I Clin Oncol 19: 1358-1362

Fliss MS, Usadel H, Caballero OL, Wu L, Buta MR, Eleff SM, Jen J, Sidransky D (2000) Facile detection of mitochondrial DNA mutations in tumors and bodily fluids. Science 287: 2017-2019

Forastiere A, Koch W, Trotti A, Sidransky D (2001) Head and neck cancer. $N$ Engl J Med 345: 1890 - 1900

Ha PK, Tong BC, Westra WH, Sanchez-Cespedes M, Parrella P, Zahurak M, Sidransky D, Califano JA (2002) Mitochondrial C-tract alteration in premalignant lesions of the head and neck: a marker for progression and clonal proliferation. Clin Cancer Res 8: $2260-2265$

Haas I, Hauser U, Ganzer U (2001) The dilemma of follow-up in head and neck cancer patients. Eur Arch Otorhinolaryngol 258: 177-183

Hill C, Doyon F, Sancho-Garnier H (1997) Epidémiologie des Cancers. Paris: Flammarion

IARC (1986) Monographs on the Evaluation of Carcinogenic Risks to Human, Tobacco Smoking, Vol. 38. Lyon: IARC Monographs

IARC (1988) Monographs on the Evaluation of Carcinogenic Risks to Humans. Alcohol Drinking, Vol. 44. Lyon: IARC Monographs

Jaskiewicz K, Venter FS, Marasas WF (1987) Cytopathology of the esophagus in Transkei. J Natl Cancer Inst 79: $961-967$

Leoni-Parvex S, Mihaescu A, Pellanda A, Monnier P, Bosman FT (2000) Esophageal cytology in the follow-up of patients with treated upper aerodigestive tract malignancies. Cancer 90: $10-16$

Mao L, Lee DJ, Tockman MS, Erozan YS, Askin F, Sidransky D (1994) Microsatellite alterations as clonal markers for the detection of human cancer. Proc Natl Acad Sci USA 91: 9871-9875

Mao L, Lee JS, Fan YH, Ro JY, Batsakis JG, Lippman S, Hittelman W, Hong WK (1996a) Frequent microsatellite alterations at chromosomes 9p21 and 3 p14 in oral premalignant lesions and their value in cancer risk assessment. Nat Med 2: 682-685
Mao L, Schoenberg MP, Scicchitano M, Erozan YS, Merlo A, Schwab D, Sidransky D (1996b) Molecular detection of primary bladder cancer by microsatellite analysis. Science 271: 659-662

McCarty PJ, Million RR (1994) History of diagnosis and treatment of cancer in head and neck. In Management of Head and Neck Cancer: a multidisciplinary approach, RR Million and NJ Cassisi (eds) 2nd edn. pp 1 -2. Philadelphia: JB Lippincott

Ogden GR (1997) The future role for oral exfoliative cytology-bleak or bright? Oral Oncol 33: 2-4

Panosetti E, Luboinski B, Mamelle G, Richard JM (1989) Multiple synchronous and metachronous cancers of the upper aerodigestive tract: a nine-year study. Laryngoscope 99: 1267-1273

Partridge M, Li SR, Pateromichelakis S, Francis R, Phillips E, Huang XH, Tesfa-Selase F, Langdon JD (2000) Detection of minimal residual cancer to investigate why oral tumors recur despite seemingly adequate treatment. Clin Cancer Res 6: 2718-2725

Pellanda A, Grosjean P, Leoni S, Mihaescu A, Monnier P, Pasche P (1999) Abrasive esophageal cytology for the oncological follow-up of patients with head and neck cancer. Laryngoscope 109: $1703-1708$

Rosas SL, Koch W, da Costa Carvalho MG, Wu L, Califano J, Westra W, Jen J, Sidransky D (2001) Promoter hypermethylation patterns of p16, O6methylguanine-DNA-methyltransferase, and death-associated protein kinase in tumors and saliva of head and neck cancer patients. Cancer Res 61: 939-942

Sanchez-Cespedes M, Esteller M, Wu L, Nawroz-Danish H, Yoo GH, Koch WM, Jen J, Herman JG, Sidransky D (2000) Gene promoter hypermethylation in tumors and serum of head and neck cancer patients. Cancer Res 60: $892-895$

Sanchez-Cespedes M, Parrella P, Nomoto S, Cohen D, Xiao Y, Esteller M, Jeronimo C, Jordan RC, Nicol T, Koch WM, Schoenberg M, Mazzarelli P, Fazio VM, Sidransky D (2001) Identification of a mononucleotide repeat as a major target for mitochondrial DNA alterations in human tumors. Cancer Res 61: 7015-7019

Shu YJ (1983) Cytopathology of the esophagus. An overview of esophageal cytopathology in China. Acta Cytol 27: 7-16

Slebos RJ, Oh DS, Umbach DM, Taylor JA (2002) Mutations in tetranucleotide repeats following DNA damage depend on repeat sequence and carcinogenic agent. Cancer Res 62: 6052-6060

Spafford MF, Koch WM, Reed AL, Califano JA, Xu LH, Eisenberger CF, Yip L, Leong PL, Wu L, Liu SX, Jeronimo C, Westra WH, Sidransky D (2001) Detection of head and neck squamous cell carcinoma among exfoliated oral mucosal cells by microsatellite analysis. Clin Cancer Res 7: 607-612 Temam S, Flahault A, Perie S, Monceaux G, Coulet F, Callard P, Bernaudin JF, St Guily JL, Fouret P (2000) p53 gene status as a predictor of tumor response to induction chemotherapy of patients with locoregionally advanced squamous cell carcinomas of the head and neck. J Clin Oncol 18: 385-394 van Houten VM, Tabor MP, van den Brekel MW, Denkers F, Wishaupt RG, Kummer JA, Snow GB, Brakenhoff RH (2000) Molecular assays for the diagnosis of minimal residual head-and-neck cancer: methods, reliability, pitfalls, and solutions. Clin Cancer Res 6: 3803-3816 